\title{
14-3-3o expression as a prognostic marker in undifferentiated nasopharyngeal carcinoma
}

\author{
SYLVIA YAT-YEE CHAN ${ }^{1,2}$, KA-FAI TO ${ }^{1-3}$, SING-FAI LEUNG ${ }^{4}$, WILLIAM WAI-LUN YIP ${ }^{5}$, \\ MICHAEL KO-FUNG MAK ${ }^{6}$, GRACE TIN-YUN CHUNG ${ }^{1,2}$ and KWOK-WAI LO ${ }^{1-3}$
}

\author{
${ }^{1}$ Department of Anatomical and Cellular Pathology, Prince of Wales Hospital, The Chinese University of Hong Kong; \\ ${ }^{2}$ State Key Laboratory in Oncology in South China, The Chinese University of Hong Kong; ${ }^{3}$ Li Ka Shing Institute \\ of Health Science, The Chinese University of Hong Kong; ${ }^{4}$ Department of Clinical Oncology, Prince of Wales \\ Hospital, The Chinese University of Hong Kong; ${ }^{5}$ Department of Pathology, Hong Kong Baptist Hospital; \\ ${ }^{6}$ Department of Clinical Pathology, Alice Ho Miu Ling Nethersole Hospital, Hong Kong, SAR, P.R. China
}

Received March 24, 2010; Accepted May 17, 2010

DOI: $10.3892 /$ or_00000941

\begin{abstract}
In this study, we investigated the expression of

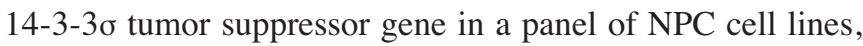
xenografts and primary tumors. Our objective was to determine the correlation between 14-3-3 $\sigma$ expression and clinical outcome in NPC. We detected reduced 14-3-3o expression in 5/6 NPC tumor lines by quantitative RT-PCR and Western blotting. By immunohistochemical staining, significant down-

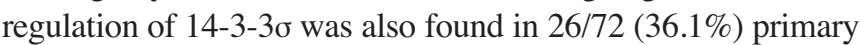
tumors of NPC patients, who were treated with curative radiotherapy. Promoter methylation was confirmed in a subset of primary tumors by methylation-specific PCR analysis. Importantly, we demonstrated that $14-3-3 \sigma$ expression is significantly associated with both overall survival (OS) and cancer-specific survival (CSS), but not with the clinical staging of NPC patients. The low 14-3-3o expression was associated with improved overall $(\mathrm{p}=0.029)$ and cancer-specific survival $(\mathrm{p}=0.042)$ on univariate analysis. $14-3-3 \sigma$ expression and staging were also independent variables to all the prognostic factors under multi-variate analysis. In conclusion, low expression of 14-3-3 $\sigma$ appears to be a valuable marker for better survival in patient with NPC. These results provide the evidence that $14-3-3 \sigma$ expression is a significant prognostic factor for NPC patients.
\end{abstract}

Correspondence to: Dr Kwok-Wai Lo, Department of Anatomical and Cellular Pathology, Prince of Wales Hospital, The Chinese University of Hong Kong, Shatin, N.T., Hong Kong, SAR, P.R. China E-mail: kwlo@cuhk.edu.hk

Abbreviation: NPC, nasopharyngeal carcinoma; EBV, EpsteinBarr virus; 14-3-3 $\sigma, 14-3-3$ sigma

Key words: 14-3-3o, nasopharyngeal carcinoma, prognostic marker, DNA methylation, radiotherapy

\section{Introduction}

14-3-3 proteins are a family of highly conserved $28-33 \mathrm{kDa}$ acidic proteins expressed in a wide range of organisms and tissues. These dimeric proteins can modulate the function of their target proteins mostly by binding with their specific phosphor-serine/threonine containing motifs. Through its ability to bind and regulate various targets, 14-3-3 proteins play key roles in multiple cellular processes including cell cycle control, checkpoints activation, signal transduction, apoptosis, transcription and translation regulation (1-4). In mammalian species, the 14-3-3 protein family consists of seven different isoforms $(\beta, \gamma, \varepsilon, \eta, \sigma, \tau, \zeta)$ encoded by distinct genes (1). Among them, 14-3-3o (also called stratifin) is regarded as a potential tumor suppressor gene and is strongly implicated in cancer development. Its transcription is commonly silenced in various cancers including breast cancer, gastric adenocarcinoma, liver cancer, bladder cancer, small cell lung carcinoma and certain squamous cell carcinoma by promoter hypermethylation. Epigenetic inactivation of 14-3-3 $\sigma$ has been demonstrated to be a very early event in breast cancer development $(5,6)$. The protein is activated by tumor suppressor protein, $\mathrm{p} 53$, in response to ionizing radiation and DNA-damaging agents (7). 14-3-3 $\sigma$ can act as a negative regulator of the cell cycle by modulating the function of multiple cycle cycle components, e.g. CDC2, cyclinB1, cyclin dependent kinase 2 (CDK2) and cyclin dependent kinase 4 (CDK4). Increased genomic instability was also found in the cancer cells with 14-3-3o silencing $(8,9)$. In addition to these functions, 14-3-3o has an anti-apoptotic role through preventing the formation of $\mathrm{Bad} / \mathrm{Bcl}-\mathrm{xL}$ complex and mitochondria translocation of $\operatorname{Bax}(10,11)$.

Nasopharyngeal carcinoma (NPC) is an Epstein-Barr virus (EBV) -associated epithelial malignancy that is prevalent in Southern China and Southeast Asia. In addition to EBV infection, multiple genetic and epigenetic alterations contribute to the transformation of nasopharyngeal epithelial cells (12). Yang et al have shown a link between loss of

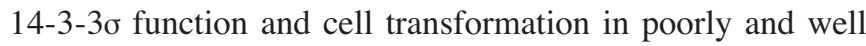
differentiated NPC cell lines (13). They showed that $14-3-3 \sigma$ 
Table I. Clinical characteristics of NPC patients.

\begin{tabular}{lcc}
\hline Characteristics & $\begin{array}{c}\text { No. of patients } \\
(\mathrm{n}=72)\end{array}$ & Percentage \\
\hline Age (years) & & \\
$\quad<40$ & 15 & 20.8 \\
$40-50$ & 31 & 43.1 \\
$51-60$ & 15 & 20.8 \\
$>60$ & 11 & 15.3 \\
Range: $19-85$ & & \\
Median: $48.6 \pm 12.1$ & & \\
Gender & & 73.6 \\
Male & 53 & 26.4 \\
Female & 19 & \\
UICC stage & & 6.9 \\
I & 5 & 45.8 \\
II & 33 & 26.4 \\
III & 19 & 20.8 \\
IV & 15 & \\
\hline
\end{tabular}

inactivated AKT activity and inhibited oncogene-activated tumorigenicity in NPC cell lines. In this study, we explored the mechanism for 14-3-3o repression and its prognostic value in the patients with EBV-positive undifferentiated NPC.

\section{Materials and methods}

Cell lines, xenografts and tumor specimens. Two NPC cell lines (C666-1, HK-1) and 4 xenografts (xeno-666, xeno2117, C15, and C17) were included in this study. Except HK-1, all of the tumor lines were EBV-positive and reported to be derived from undifferentiated NPCs (14-17). The EBVpositive NPC cell line C666-1 was established from xeno666 in our laboratory (15). HK-1 is an EBV-negative cell line from a recurrent well-differentiated tumor (14). An immortalized normal nasopharyngeal epithelial cell line NP460 served as the controls in this study (18). The immortalized nasopharyngeal cells NP460 and NPC cell lines were grown in defined keratinocyte SFM medium and RPMI-1640 with $10 \%$ fetal bovine serum (Invitrogen, Carlsbad, CA), respectively.

A total of 72 cases of formalin-fixed paraffin-embedded undifferentiated NPC were recruited from the Department of Anatomical and Cellular Pathology at the Prince of Wales Hospital, The Chinese University of Hong Kong for retrospective study. All of these samples were reviewed by two independent pathologists as undifferentiated NPC according to the WHO classification. The clinical parameters are summarized in Table I. The age of the patients ranged from 19 to 85 years with a median age of 48.6 years. Seventy-four percent were men (53 of 72 ) and $26 \%$ were women (19 of 72). They were classified as 5 in Stage 1, 33 in stage 2, 19 in stage 3 and 15 in stage 4 according to the fifth (1997) edition of the UICC-American Joint Committee on Cancer staging a.

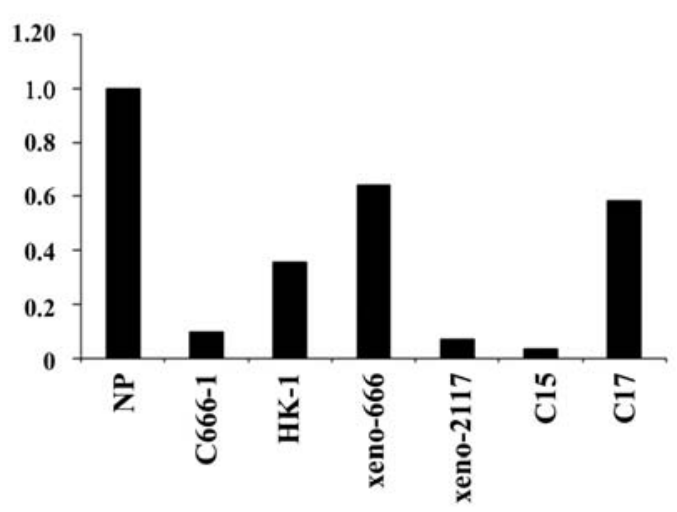

b.

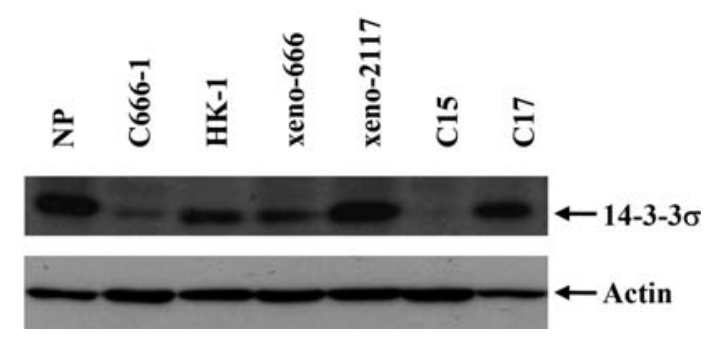

Figure 1. Expression of 14-3-3 $\sigma$ in NPC. (a) Quantitative RT-PCR analysis

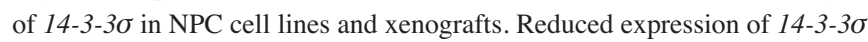
was found in all tumor lines as compared with the normal nasopharyngeal cells. (b) Western blot analysis showed reduce expression of 14-3-3 $\sigma$ in all NPC tumor lines except xeno-2117.

criteria (19). All these patients received standard radiotherapy only and with a median follow-up of 5 years.

Quantitative RT-PCR. Total RNA was extracted from the cell lines and xenografts using TRIzol reagent (Invitrogen). For real-time quantitative RT-PCR analysis, the samples were analyzed as described previously (20). The primers used

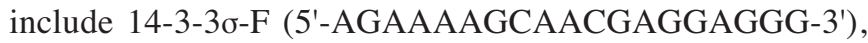

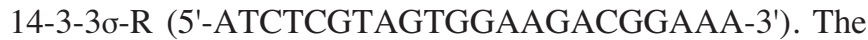
primers for control $\beta$-actin transcripts are $\beta$-actin-F (5'-CGC GAGAAGATGACCCAGAT-3') and B-actin-R (5'GTACG GCCAGAGGCGTACAG-3'). The PCR conditions were: 1 cycle of $95^{\circ} \mathrm{C}$ for $12 \mathrm{~min} ; 35$ cycles of $95^{\circ} \mathrm{C}$ for $30 \mathrm{sec}$, $60^{\circ} \mathrm{C}$ for $30 \mathrm{sec}, 72^{\circ} \mathrm{C}$ for $1 \mathrm{~min}$ and 1 cycle of $72^{\circ} \mathrm{C}$ for $7 \mathrm{~min}$. All reactions were performed in triplicate. The relative mRNA

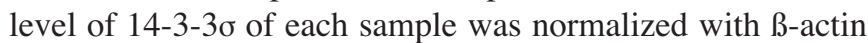
and calculated using the 2[-Delta Delta $\mathrm{C}(\mathrm{T})]$ method as described (20).

Western blotting. The expression of 14-3-3 $\sigma$ in NPC cell lines and xenografts was investigated by Western blotting as dsecribed (21). Anti-14-3-3 $\sigma$ monoclonal antibody at dilution 1:1000 (clone AB9742, Chemicon, The Netherlands) and anti-actin polyclonal antibody at dilution 1:500 (Santa Cruz Biotechnology, Santa Cruz, CA) were used in our study.

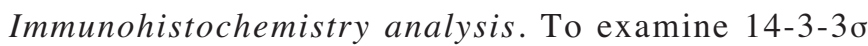
expression in primary tumors, immunohistochemical staining 
a

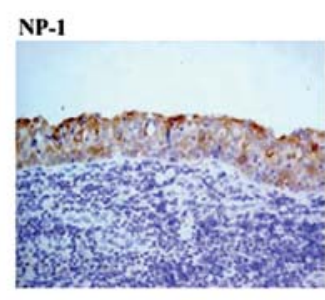

b
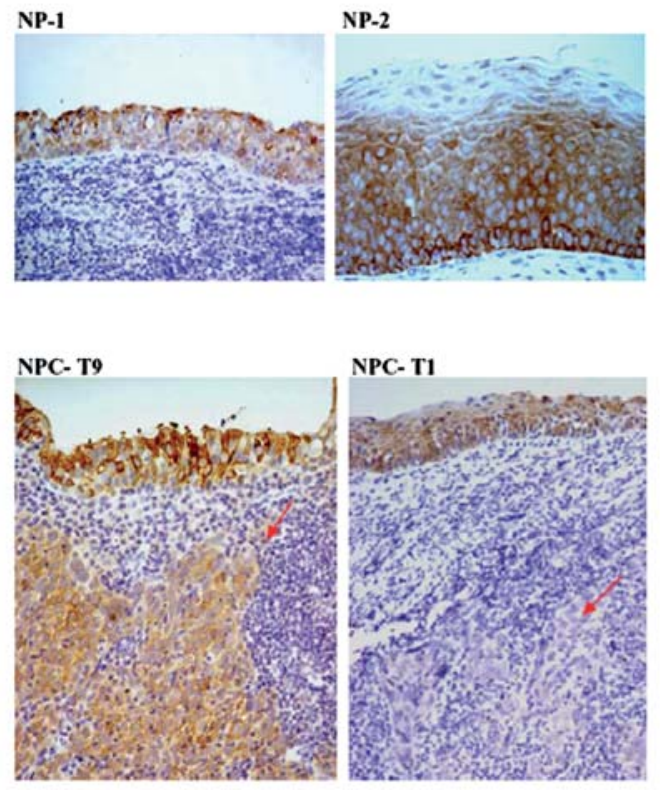

C
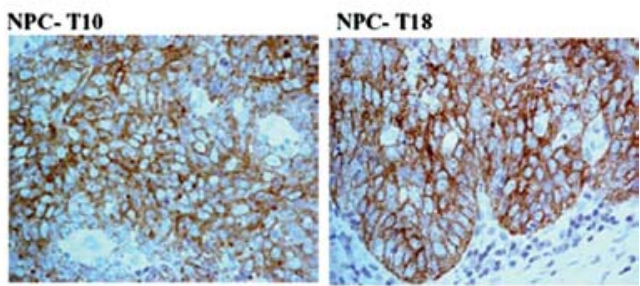

d
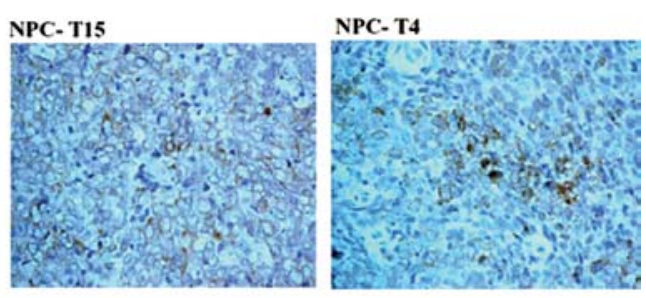

e

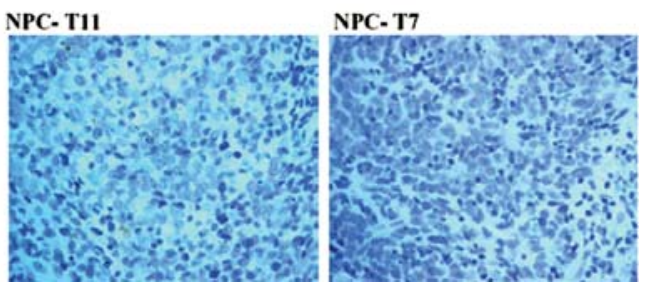

Figure 2. Expression of 14-3-3 $\sigma$ in normal nasopharyngeal epithelia and primary NPC tumors. (a) By immunohistochemical staining, strong positive signal of 14-3-3 $\sigma$ was detected in the membrane and cytoplasm of normal nasopharyngeal epithelial cells (NP-1, NP-2) but not in the adjacent stromal tissues. (b) While high 14-3-3 $\sigma$ expression was consistently observed in adjacent normal epithelium, strong and weak 14-3-3 $\sigma$ signals were found in the cancer cells (red arrows) of primary tumors, NPC-T9 and NPC-T1, respectively. (c) and (d) shows, respectively, the represent tumor cases with high and moderate 14-3-3 $\sigma$ expression. (e) Weak or absence of 14-3-3 $\sigma$ expression were demonstrated in primary tumors NPC-T11 and NPC-T7.

was carried out on $4 \mu \mathrm{m}$ formalin fixed, paraffin-embedded tissue sections as described (21). Monoclonal antibody to human 14-3-3o (clone 1433S01, RDI, Concord, MA) was used at a dilution of 1:100. A semiquantitative four-tiered system (0 to 3 ) was adopted to score the degree of immuno-

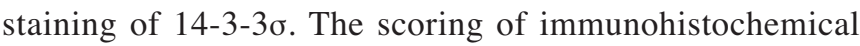
staining takes into account both the extensiveness and intensity of staining. The extensiveness with score $0-3$ is defined as score $0=0 \%$, score $1=>0 \%$ to $<30 \%$, score $2=$ $30 \%$ to $<60 \%$, score $3=60 \%$ or above. An intensity score is assigned to each sample with score $0=$ absence of staining and score 1-3 corresponding to weak, moderate and strong staining. The total score corresponds to the products of extensiveness and intensity. Thus, the maximum score is $3 \mathrm{x}$ $3=9$ and minimum score is $0 \times 0=0$. Areas of necrosis or fibrosis were excluded. All the slides were reviewed independently by two pathologists.

Statistical analysis. The cancer specific survival was calculated using the Kaplan-Meier method and the comparison between patients with different stages was performed with the logrank test. Cox's proportional hazards modeling of factors potentially related to survival was performed to identify which factors might have a significant influence on survival. $\mathrm{P}<0.05$ were considered to be statistically significant. Statistical analyses were performed using SPSS 13.0.0 (SPSS Inc., Chicago, IL, USA).
Methylation-specific PCR (MSP). The promoter methylation of 14-3-3 $\sigma$ of the tumor samples was examined by MSP analysis as described (20). Briefly, $1 \mu \mathrm{g}$ of genomic DNA extracted from the NPC samples was treated with sodium bisulfite using the CpGenome DNA modification kit (Intergen, Burlington, MA). Primers specific for methylated sequence (sense 5'-TGGTAGTTTTTATGAAAGGCGTC-3'; antisense 5'CCTCTAACCGCCCACCACG-3') and unmethylated sequence (sense 5'ATGGTAGTTTTTATGAAAGGTGTT-3'; antisense 5'CCCTCTAACCACCCACCACA') yielded PCR products of 105 and $107 \mathrm{bp}$, respectively. The PCR conditions were: 1 cycle of $95^{\circ} \mathrm{C}$ for $12 \mathrm{~min} ; 30$ cycles of $95^{\circ} \mathrm{C}$ for $30 \mathrm{sec}$, $60^{\circ} \mathrm{C}$ for $30 \mathrm{sec}$ and $72^{\circ} \mathrm{C}$ for $1 \mathrm{~min}$; and 1 cycle of $72^{\circ} \mathrm{C}$ for 4 min. Universal methylated human male genomic DNA (Intergen) was used as the positive control.

\section{Results}

Expression of 14-3-30 in NPC cell lines. In our recent transcription profiling study, 14-3-3 $\sigma$ expression was lower in an EBV-positive NPC cell line, C666-1, than that in normal nasopharyngeal epithelial outgrowths (HTMseq, http://bioinfo. amc.uva.nl/HTMseq/controller). To confirm the downregulation of $14-3-3 \sigma$ in NPC, we investigated the $14-3-3 \sigma$ transcription in 6 NPC cell lines and xenografts using quantitative RT-PCR analysis. Decreased expression of 14-3-3o transcripts was found in all NPC tumor lines. In particular, 
a.

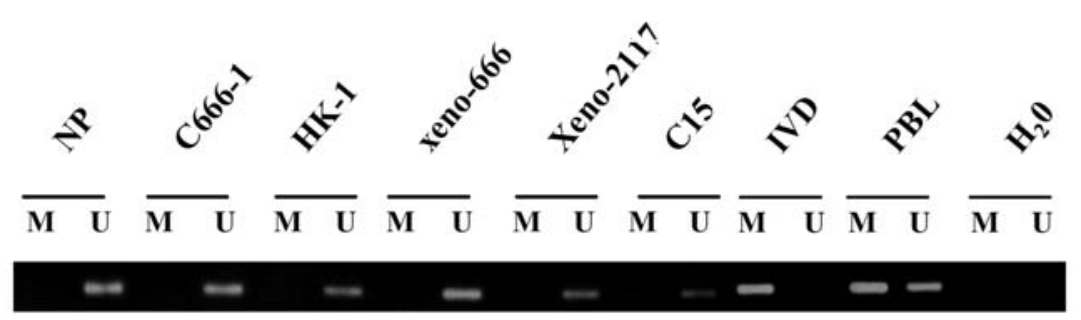

b.
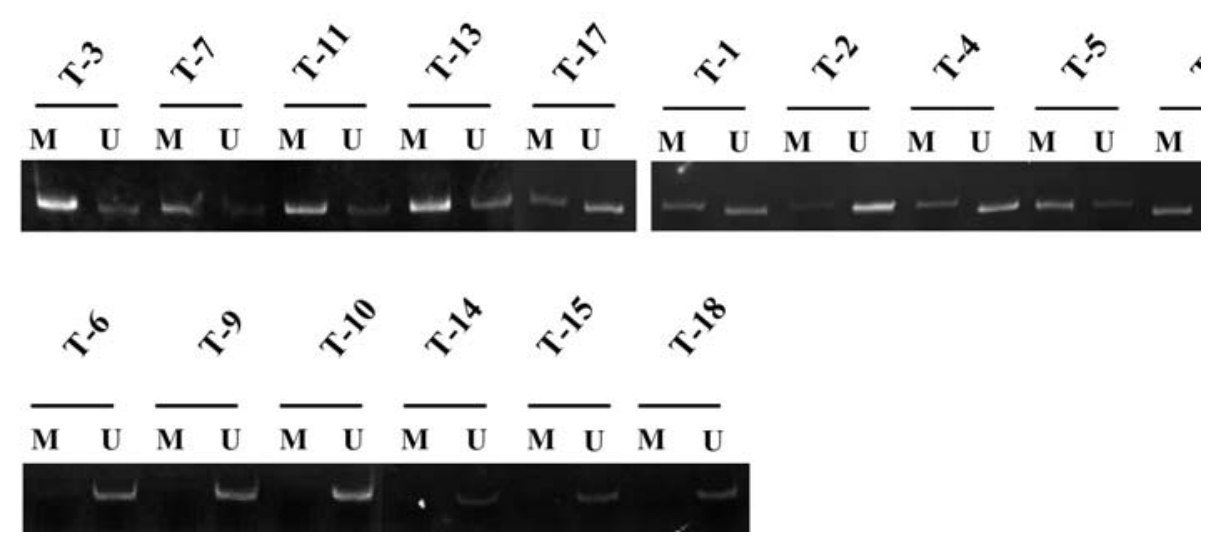

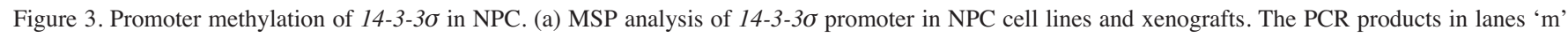
and ' $u$ ' indicate the presence of methylated and unmethylated alleles, respectively. Preipheral blood lymphocyte (PBL) served as unmethylated control while in vitro methylated DNA (IVD) was used as methylated control. None of the NPC cell lines or xenografts showed aberrant methylation of the $14-3-3 \sigma$ gene.

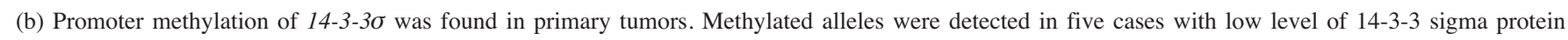
expression (T-3, T-7, T-11, T13, and T17).

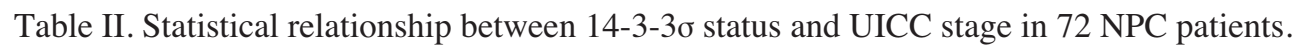

\begin{tabular}{|c|c|c|c|c|}
\hline \multirow[b]{2}{*}{ Prognostic variables } & \multicolumn{3}{|c|}{$14-3-3 \sigma$ expression (Total score) } & \multirow[b]{2}{*}{ P-value } \\
\hline & $\begin{array}{c}\text { Low }(0-3) \\
(\mathrm{n}=26 ; 36.1 \%)\end{array}$ & $\begin{array}{c}\text { High (4-9) } \\
(\mathrm{n}=46 ; 63.9 \%)\end{array}$ & $\begin{array}{c}\text { Total }(\%) \\
(\mathrm{n}=72 ; 100 \%)\end{array}$ & \\
\hline Gender & & & & $0.783^{\mathrm{a}}$ \\
\hline Male & 20 & 33 & $53(73.61)$ & \\
\hline Female & 6 & 13 & $19(26.39)$ & \\
\hline Age (Years) & & & & $0.435^{\mathrm{b}}$ \\
\hline Mean & 33.94 & 37.95 & $-(-)$ & \\
\hline UICC stage & & & & $0.692^{c}$ \\
\hline I & 1 & 4 & $5(6.94)$ & \\
\hline II & 12 & 21 & $33(45.83)$ & \\
\hline III & 6 & 13 & $19(26.39)$ & \\
\hline IV & 7 & 8 & $15(20.83)$ & \\
\hline
\end{tabular}

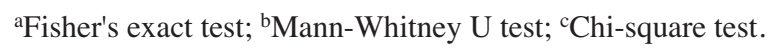

14-3-3 $\sigma$ transcription was highly reduced in the tumor lines C666-1, xeno-2117 and C15 (Fig. 1a). Decreased 14-3-3o protein expression was also observed in all NPC tumor lines except xeno-2117 (Fig. 1b). These findings showed that 14-3-3 $\sigma$ expression is commonly downregulated in NPC cell lines and xenografts.
Expression of 14-3-3o in primary NPC samples. To elucidate

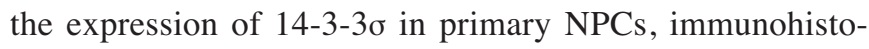
chemical staining was performed on 72 archival paraffin embedded tumor specimens. Normal nasopharyngeal epithelia adjacent to NPC are strongly positive for 14-3-3o expression. Representative membrane and cytoplasmic staining of 14-3-3o 
a.

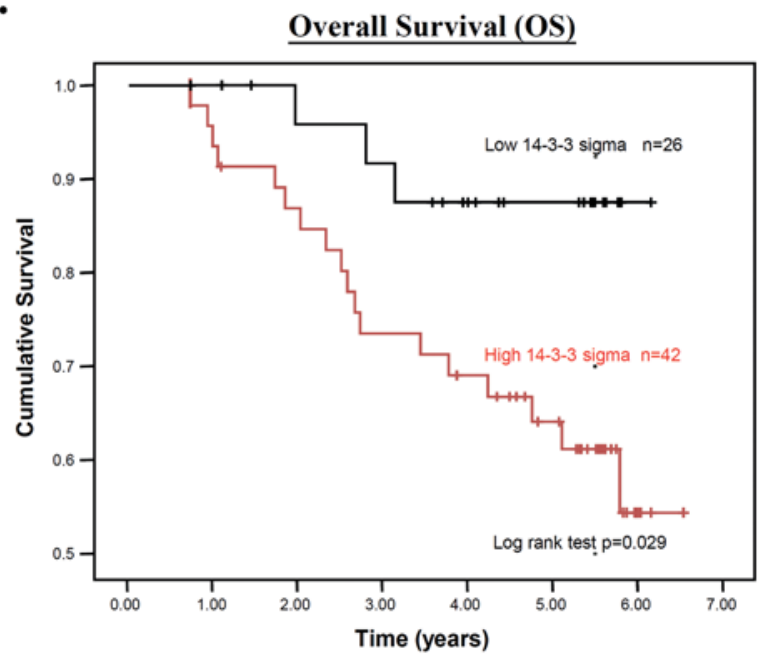

c.

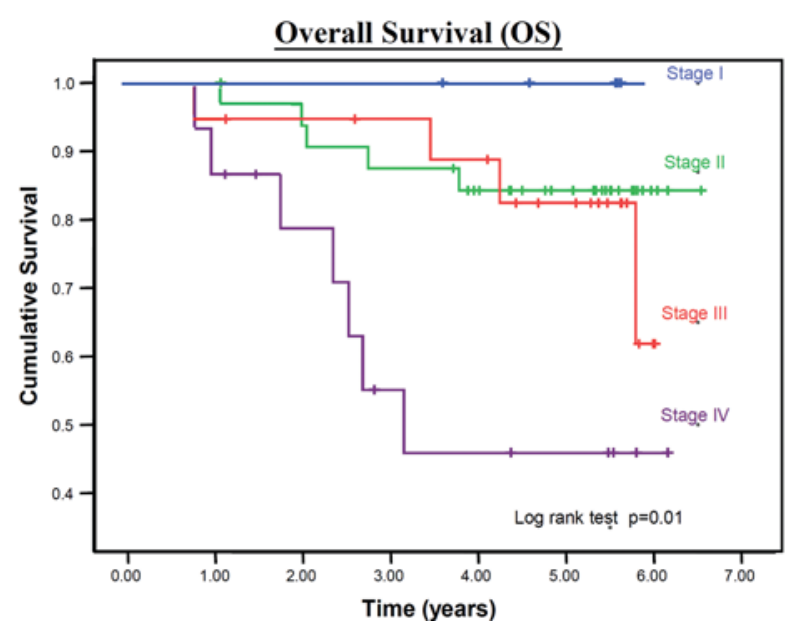

b.

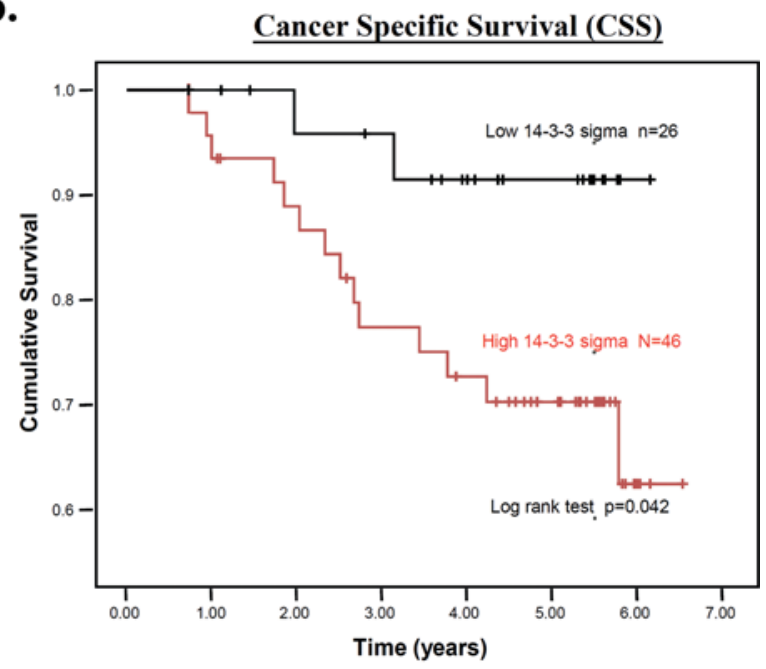

d.

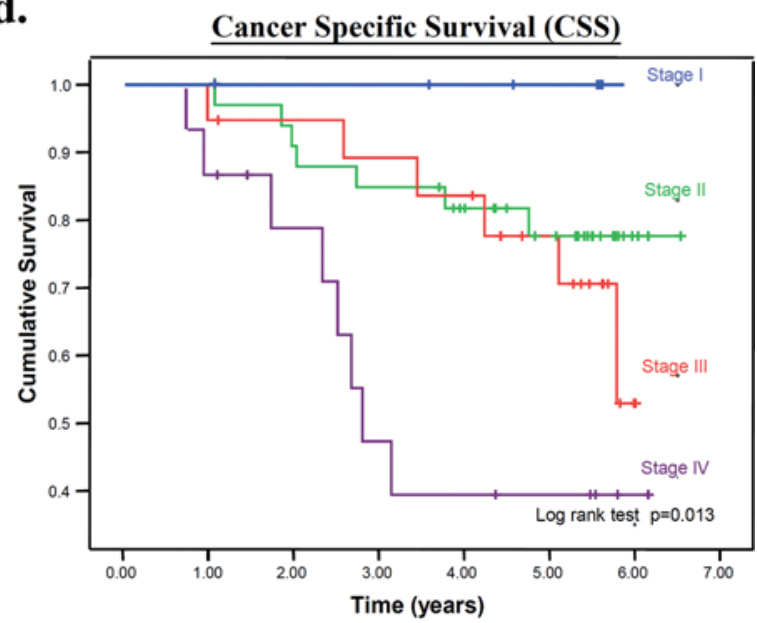

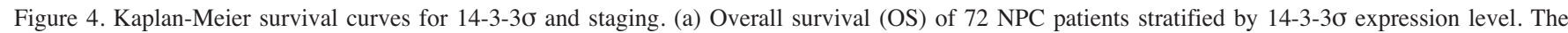
survival period of the patients with high 14-3-3 $\sigma$ expression (total score $\geq 3$ ) is significantly shorter than that of the patients with low 14-3-3 $\sigma$ expression (total score <3) ( $\mathrm{p}=0.029$ log rank). (b) Positive 14-3-30 expression ( $\mathrm{p}=0.042$ log rank) was significantly correlated with shorter cancer specific survival (CSS). A Kaplan-Meier plot for (c) overall survival (OS) and (d) cancer specific survival (CSS) as a function of staging, for the 72 patients in this study. Significant association between staging and OS $(\mathrm{p}=0.013)$ and CSS $(\mathrm{p}=0.01)$ are shown.

in a normal nasopharyngeal epithelium was demonstrated in Fig. 2a. The 14-3-3o positive malignant cells also display both membrane and cytoplasmic staining similar to that in the normal epithelium (Fig. 2b). Reactive lymphocytes and the adjacent connective tissue are negative for $14-3-3 \sigma$ in all cases.

Among the 72 cases of primary undifferentiated NPCs, various 14-3-3o staining patterns were observed. Fig. 2c and $2 \mathrm{~d}$ show the cases with strong and moderate 14-3-3 $\sigma$ immunoreactivity, respectively. Representative cases with

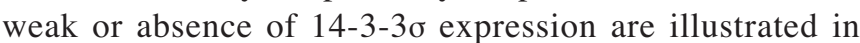
Fig. 2e. Based on the semiquantative four-tiered system, 26

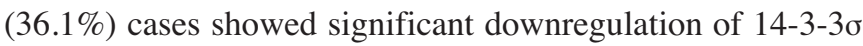
expression which is defined as having a total score of $<3$. This result showed that loss of 14-3-3 $\sigma$ expression occurred in a subset of primary tumors.

Aberrant methylation of 14-3-3o in NPC. To explore the

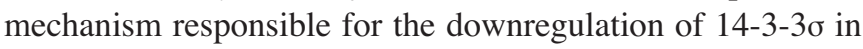
NPC, we have investigated the methylation status of 14-3-3o
CpG islands in the 2 NPC cell lines, 4 xenografts, and 18 primary tumors by MSP assay. Transcriptional silencing of 14-3-3 $\sigma$ by promoter hypermethylation is common in multiple human cancers. In primary NPCs, we detected promoter hypermethylation of $14-3-3 \sigma$ in $11 / 18$ (63\%) cases. Among these 11 cases, 5 show absence or weak 14-3-3o expression (total score: <3) while 4 cases show moderate expression. In 2 methylated cases with high score for 14-3-3o staining, heterogeneous loss of 14-3-3 expression were also observed. Moderate to high 14-3-3 sigma expression were detected in the 7 cases without promoter methylation. However, the 6 cell lines and xenografts with reduced 14-3-3o transcript expression showed no aberrant methylation in the $5^{\prime} \mathrm{CpG}$ island. Promoter hypermethylation was not detected in the normal nasopharyngeal epithelial cells. The finding suggested that promoter hypermethylation is one of the mechanisms for downregulation of 14-3-3 $\sigma$ in NPC (Fig. 3).

Correlation between 14-3-30 expression and clinical parameters. The significance of 14-3-3 $\sigma$ expression was analyzed 
in regard to the clinical parameters including age, gender, clinical stage and survival of NPC patients. Expression of 14$3-3 \sigma$ in primary NPC was not correlated with age, gender, and clinical stage of the patients (Table II). However, a significant correlation between high 14-3-3 $\sigma$ expression and poorer overall survival (OS, $\mathrm{p}=0.029$ ) was found by KaplanMeier analysis and log-rank test (Fig. 4a). The low 14-3-3o expression group $(n=26)$ had better survival, whereas the high 14-3-3o expression group $(n=46)$ had a poorer clinical outcome. Moreover, 14-3-3o expression was also associated with cancer specific survival ( $\mathrm{p}=0.042$ ) (Fig. 4b). The finding implied that down-regulation of $14-3-3 \sigma$ was a prognostic marker of NPC patients. Moreover, there was a statistically significant association between staging and overall survival $(\mathrm{p}=0.013)$ and cancer specific survival $(\mathrm{p}=0.01)$ using KaplanMeier analysis and log-rank test (Fig. 4c and d). Under the Cox regression and multi-variate analysis, 14-3-3o expression and staging were independent variables to all the prognostic factors.

\section{Discussion}

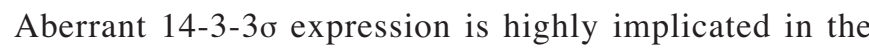
development of multiple human cancers. However, its role in NPC tumorigenesis is unclear. In this study, we found evidence that the $14-3-3 \sigma$ gene expression is commonly downregulated at both transcriptional and translational levels in undifferentiated NPC cells. Previously, we demonstrated that promoter methylation is the major mechanism for inactivation of critical tumor suppressors (e.g. p16, RASSF $1 A$, TSLC1, and DLEC1) in NPC. Loss of 14-3-3o expression has been frequently reported in many human epithelial cancers including breast, gastric, lung and prostate cancers as a result of promoter hypermethylation (22-25).

Studies on the precursor lesions of breast and prostate cancers also suggested that inactivation of the $14-3-3 \sigma$ is an early event during carcinogenesis in these cancers $(26,27)$. However, only a subset of primary NPC tumors showed the epigenetic inactivation of $14-3-3 \sigma$ in this study. Downregulation of $14-3-3 \sigma$ was found in a number of primary tumors and all tumor lines in which no promoter methylation was detected. The results implied that other mechanisms for 14-3-3o repression may be involved. For example, modulating 14-3-3o proteolysis by estrogen-responsive finger protein (Efp) has been reported previously (28). The findings implied that promoter hypermethylation is only one of the mechanisms for 14-3-3o suppression in a subset of EBVpositive primary NPCs.

As a p53-regulator that is involved in DNA damage induced cell cycle arrest, 14-3-3o protein is considered as a tumor suppressor for maintaining genetic stability (7). A recent study on two EBV-negative cell lines (CNE-1 and CNE-2) containing p53 mutation (p53 Thr280) has demonstrated that 14-3-3o was able to suppress tumor growth (13). The group found that 14-3-3o interacted with protein kinase B/Akt and negatively regulated the activity of Akt. Therefore, inactivation of 14-3-3o may contribute to the activation of Akt signaling transduction pathways and transformation of NPC cells.
In the current study, we showed that patients with downregulation of 14-3-3o have a better overall survival and cancer specific survival. High 14-3-3o expression in the tumor sample predicts poor outcome of the patients with undifferentiated NPC. The significant correlation of 14-3-3o overexpression with reduced survival time was also reported in patients with colorectal carcinoma. The colorectal cancer cells with no 14-3-3o expression are sensitive to chemotherapy-induced

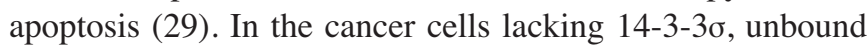
Bax is translocated to mitochondria, mediates mitochondrial permeability transition, and subsequently in cytochrome $\mathrm{C}$ (11). This may sensitize the cells for rapid progression into apoptosis through caspase-3 activation. For NPC patients, radiotherapy is the mainstay treatment and all patients in this study were treated with radiotherapy only. The expression of 14-3-3 $\sigma$ may associate with the sensitivity of the tumor cells to this treatment. However, further study is needed to define

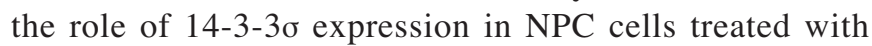
either $\gamma$-irradiation or chemotherapeutic agents. The findings may help to predict the sensitivity of radiotherapy and stratify patients who may require multimodality treatment.

In this study, we comprehensively investigated the correlation of 14-3-3o expression and multiple clinical parameters in NPC patients. Importantly, we demonstrated

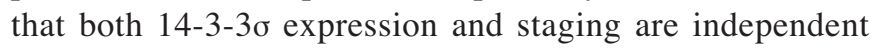
prognostic factors for NPC patients.

\section{Acknowledgements}

This study was conducted with the support of Michael and Betty Kadoorie Cancer Genetics Research Program II (MBKCGRPII), Li Ka Shing Institute of Health Science, and Hong Kong Research Grant Council (CUHK 4413/05M).

\section{References}

1. Aitken A, Collinge DB, van Heusden BP, Isobe T, Roseboom PH, Rosenfeld G and Soll J: 14-3-3 proteins: a highly conserved, widespread family of eukaryotic proteins. Trends Biochem Sci 17: 498-501, 1992.

2. Bridges D and Moorhead GBG: 14-3-3 proteins: a number of functions for a numbered protein. Sci STKE 2005: re 10, 2005.

3. Tzivion G, Gupta VS, Kaplun L and Balan V: 14-3-3 proteins as potential oncogenes. Semin Cancer Biol 16: 203-213, 2006.

4. Peng CY, Graves PR, Thoma RS, Wu Z, Shaw AS and PiwnicaWorms H: Mitotic and G2 checkpoint control: regulation of 14-3-3 protein binding by phosphorylation of Cdc25C on serine-216. Science 227: 1501-1505, 1997.

5. Lodygin D and Hermeking H: Epigenetic silencing of 14-3-3 sigma in cancer. Semin Cancer Biol 16: 214-224, 2006.

6. Horie-Inoue K, and Inoue S: Epigenetic and proteolytic inactivation of 14-3-3sigma in breast and prostate cancers. Semin Cancer Biol 16: 235-239, 2006.

7. Hermeking H, Lengauer C, Polyak K, He TC, Zhang L, Thiagalingam S, Kinzler KW and Vogelstein B: 14-3-3 sigma is a p53-regulated inhibitor of G2/M progression. Mol Cell 1: 3-11, 1997.

8. Chan TA, Hermeking H. Lengauer C, Kinzler KW and Vogelstein B: 14-3-3Sigma is required to prevent mitotic catastrophe after DNA damage. Nature 401: 616-620, 1999.

9. Laronga C, Yang HY, Neal C and Lee MH: Association of the cyclin-dependent kinases and 14-3-3 sigma negatively regulates cell cycle progression. J Biol Chem 275: 2310623112, 2000.

10. Subramanian RR, Masters SC, Zhang $\mathrm{H}$ and Fu H: Functional conservation of 14-3-3 isoforms in inhibiting bad-induced apoptosis. Exp Cell Res 271: 142-151, 2001. 
11. Samuel T, Weber HO, Rauch P, Verdoodt B, Eppel JT, McShea A, Hermeking $\mathrm{H}$ and Funk JO: The G2/M regulator 14-3-3 sigma prevents apoptosis through sequestration of Bax. J Biol Chem 276: 45201-45206, 2001.

12. Lo KW, To KF and Huang DP: Focus on nasopharyngeal carcinoma. Cancer Cell 5: 423-428, 2004

13. Yang H, Zhao R and Lee MH: 14-3-3sigma, a p53 regulator, suppresses tumor growth of nasopharyngeal carcinoma. Mol Cancer Ther 5: 253-260, 2006.

14. Huang DP, Ho JH, Poon YF, Chew EC, Saw D, Lui M, Li CL, Mak LS, Lai SH and Lau WH: Establishment of a cell line (NPC/HK1) from a differentiated squamous carcinoma of nasopharynx. Int J Cancer 26: 127-132, 1980.

15. Cheung ST, Huang DP, Hui ABY, Lo KW, Ko CW, Tsang YS, Wong N, Whitney BM and Lee JC: Nasopharyngeal carcinoma cell line (C666-1) consistently harboring Epstein-Barr virus. Int J Cancer 83: 121-126, 1999.

16. Huang DP, HO JH, Chan WK, Lau WH and Lui M: Cytogenetics of undifferentiated nasopharyngeal carcinoma xenografts from southern Chinese. Int J Cancer 43: 936-939, 1989.

17. Busson P, Ganem G, Flores P, Mugneret F, Clausse B, Caillou B, Braham K, Wakasugi H, Lipinski M and Tursz T: Establishment and characterization of three transplantable EBV-containing nasopharyngeal carcinomas. Int J Cancer 42: 599-606, 1988.

18. Li HM, Man C, Jin Y, Deng W, Yip YL, Feng HC, Cheung YC, Lo KW, Meltzer PS, Wu ZG, Kwong YL, Yuen AP and Tsao SW: Molecular and cytogenetic changes involved in the immortalization of nasopharyngeal epithelial cells by telomerase. Int J Cancer 119: 1567-1576, 2006

19. Fleming ID, Cooper JS, Henson DE, et al (eds): AJCC Cancer Staging Manual (5th edition). Lippincott-Raven, Philadelphia, PA, pp31-39, 1997.

20. Kwong J, Chow LS, Wong AY, Hung WK, Chung GT, To KF, Chan FL, Daigo Y, Nakamura Y, Huang DP and Lo KW: Epigenetic inactivation of the deleted in lung and esophageal cancer 1 gene in nasopharyngeal carcinoma. Genes Chromosomes Cancer 46: 171-180, 2007.

21. Hui AB, Or YY, Takano H, Tsang RK, To KF, Guan XY, Sham JS, Hung KW, Lam CN, van Hasselt CA, Kuo WL, Gray JW, Huang DP and Lo KW: Array-based comparative genomic hybridization analysis identified cyclin D1 as a target oncogene at 11q13.3 in nasopharyngeal carcinoma. Cancer Res 65: 8125-8133, 2005.
22. Ferguson At, Evron E, Umbricht CB, Pandita TK, Chan TA, Hermeking H, Marks JR, Lambers AR, Futreal PA, Stampfer MR and Sukumar S: High frequency of hypermethylation at the 14-3-3 sigma locus leads to gene silencing in breast cancer. Proc Natl Acad Sci USA 97: 6049-6054, 2000.

23. Suzuki H, Itoh F, Toyota M, Kikuchi T, Kakiuchi H and Imai K: Inactivation of the 14-3-3 sigma gene is associated with $5{ }^{\prime} \mathrm{CpG}$ island hypermethylation in human cancers. Cancer Res 60: 4353-4357, 2000.

24. Osada H, Tatematsu Y, Yatabe Y, Nakagawa T, Konishi H, Harano T, Tezel E, Takada M and Takahashi T: Frequent and histological type-specific inactivation of 14-3-3 sigma in human lung cancers. Oncogene 21: 2418-2424, 2002.

25. Henrique R, Jerónimo C, Hoque MO, Carvalho AL, Oliverira J, Teixeira MR, Lopes C and Sidransky D: Frequent 14-3-3 sigma promoter methylation in benign and malignant prostate lesions. DNA Cell Biol 24: 264-269, 2005.

26. Umbricht CB, Evron E, Gabrielson E, Ferguson A, Marks J and Sukumar S: Hypermethylation of 14-3-3 sigma (stratifin) is an early event in breast cancer. Oncogene 20: 3348-3353, 2001.

27. Cheng L, Pan CX, Zhang JT, Zhang S, Kinch MS, Li L, Baldridge LA, Wade C, Hu Z, Koch MO, Ulbright TM and Eble JN: Loss of 14-3-3 sigma in prostate cancer and its precursors. Clin Cancer Res 10: 3064-3068, 2004.

28. Urano T, Saito T, Tsukui T, Fujita M, Hosoi T, Muramatsu M, Ouchi Y and Inoue S: Efp targets 14-3-3 sigma for proteolysis and promotes breast tumor growth. Nature 417: 871-875, 2002.

29. Perathoner A, Pirkebner D, Brandacher G, Spizzo G, Stadlmann S, Obrist P, Marqreiter R and Amberger A: 14-3-3 sigma expression is an independent prognostic parameter for poor survival in colorectal carcinoma patients. Clin Cancer Res 11: 3274-3279, 2005. 